\title{
Gender Differences in Perceived Equality and Personal Knowledge System Development on Personal Learning Network
}

\author{
Regina Juchun Chu \\ Center for Teacher Education, National Tsing Hua University, Hsinchu City, Taiwan \\ Email: chu@mx.nthu.edu.tw
}

Received 28 October 2014; revised 29 November 2014; accepted 5 December 2014

Copyright (C) 2014 by author and Scientific Research Publishing Inc.

This work is licensed under the Creative Commons Attribution International License (CC BY). http://creativecommons.org/licenses/by/4.0/

(c) (i) Open Access

\section{Abstract}

The purpose of this research is to investigate how personal learning network (PLN) facilitates individuals to build up their own epistemologies of the interpretation for their knowledge system. Based on three interviews and literature reviews, this study intends to develop and validate a personal epistemology development scale (PEDS) on PLNs to understand learner knowledge constructions. 561 valid data from the participants in two studies (exploratory and confirmatory factor analysis) were analyzed for the research purpose. The results of these studies supported an 18-item, 4-factor PEDS: description, analysis, vision, and strategy. The results also reveal that equality significantly influences the process of theory development especially for the stage of vision. The result moreover shows gender differences existing in the perception of equality on PLN environment, in the description and in the vision stages.

\section{Keywords}

Personal Learning Network, Adult Learning, Constructivism

\section{Introduction}

Social network tools, such as blogs, wiki, twitter, facebook, etc., have been widely used as learning media in formal and informal education, which contributes the concept development of personal learning network (PLN). By interacting with members online, people increase the opportunities to approach global community and receive multiple resources of feedback. PLN has been introduced for the past decade [1]. People use it as journal writing, sharing experiences, showing off achievements, connecting with friends and community, even for commercial use. Writing is a basic form of PLN [2]. Since writing and readings can help individuals construct 
their own theories, this study intends to explore the learning activities on PLN to examine the role of perceived equality in constructing personal knowledge system for both genders.

The American activist Bunch [3] asserts that to promote the power of minority, ethnic or gender, reading and writing are important channels to start with. She provides a concept of personal theory construction for learners to emphasize their own power and transformation into actions. Only the very specific individual can explain what they have done and what must been done [4]. The disadvantaged groups should learn how to build their own theory rather than accept the dominant value of the oppressors.

\subsection{Personal Epistemology Development}

Kerlinger [5] has defined theory as a set of interrelated concepts, definitions and propositions of phenomena put together with a systematic view of interrelations with the purpose of describing, explaining or predicting the phenomenon. Theory, in another word, is a bond between facts with fact assimilations [6]. As to personal epistemology development, it refers to the organization or arrangement of the interrelation of parts to give the entity or phenomenon. Its process elements include ideas, creativity, discipline of imagination, logic, methods and procedures, and standards of conduct. When reviewing the elements, people would think that a theory construction must be implemented by a trained or knowledgeable scholar. Bunch and Frost [3] assert that every single individual has the ability and the right to construct theories. The construction is not privileged to scholars. The activist stresses that the power to define oneself and explain the experiences of his/her context should be enhanced and respected especially for ethnic minority, females, and sociostructure disadvantaged group. Bunch [7], and Bunch and Frost [3] provide four stages for personal epistemology construction: description, analysis, vision and strategy. These stages are the frame for the observation of this study on the work of PLN writings.

\subsection{Equality}

The perception of equality for PLN users is important to their learning decisions. Bunch [7], and Bunch and Frost [3] think that only through the enhancement of perceptions of equality of individuals' relationships with others, the possibility of personal theory development can be realized. The equality includes the equal power between teachers and students, student peers, feminist equality, and the equal power between readers and their readings [8]. The assumption is that when people raise their power and dialogue with the knowledge source, instead of completely acceptance, then it is possible for the individual to develop his/her own belief and then transform.

\subsection{Purpose of the Study}

The purpose of this study is to develop and validate a personal epistemology development scale (PEDS) with the PLN. This research also intends to explore the relationship between perceived equality and the stages of theory construction. Gender differences between female and male PLN writers in their personal theory/epistemology development and perceived equality will be discussed in this paper.

\section{Method}

Before you begin to format your paper, first write and save the content as a separate text file. Keep your text and graphic files separate until after the text has been formatted and styled. Do not use hard tabs, and limit use of hard returns to only one return at the end of a paragraph. Do not add any kind of pagination anywhere in the paper. Do not number text heads - the template will do that for you.

Finally, complete content and organizational editing before formatting. Please take note of the following items when proofreading spelling and grammar:

\subsection{Study 1: Pilot Test}

\subsubsection{Data Collection}

This study assesses PLN users' perceived power relations existing in their PLN for their own personal theory making. The data were collected from an online survey. This study applied a purposive sample to target Internet users who are going online for writing journals on PLNs on a daily basis. A total of 600 PLNs were selected. Survey responses were returned as data files, containing the data and time of receipt as well as the respondents' Internet survey addresses. Internet server and e-mail addresses were used to remove duplicate responses. A total 
of 561 PLN users participated in this study and fill out the survey on line.

\subsubsection{Participants}

For pilot test, 150 PLN writers were included. All participants were invited to volunteer. The mean age of the participants were $30.17(\mathrm{SD}=7.68)$ and there were $76(50.67 \%)$ male. The gender ratio was even in this pilot study. Respondents on average have used the Internet for more than 9 years, spending an average of 24.17 hours per week with the Internet related activities and 15.24 hours a week on writing their own PLNs or browsing PLNs.

\subsubsection{Data Analysis}

This study tested and refined the survey items proposed for the scale. These items were presented by a 5-point Likert type scale with $1=$ strongly disagree and $5=$ strongly agree. Factor analysis was run to identify the theory construction stages for PLN users. 19 statements were developed from interviews and used for factored by principal component analysis (PCA) with varimax rotation (orthogonal), which assigned the items to a specific factor when the primary loadings were greater than 0.50 .

\subsubsection{Results}

An exploratory factor analysis (EFA) using PCA with varimax rotation was administered on the 19 items to explore the underlying structure of the scale. The criteria for determining the number of components to retain were Kaiswer's [9] eigenvalue greater than 1 . The initial solution yielded four components with eigenvalues exceeding 1, accounting for a total of $65.59 \%$ of the variance. Following the recommendations by Hair, Black, Babin and Anderson [10], items with loadings greater than 0.50 have practical significance. On this basis, all 19 items were retained for further analysis. At this stage, the four factors were description (DE, 6 items), analysis (AN, 4 items), vision (VI, 6 items), strategy (ST, 3 items), accordant with the original theory. The descriptive statistical analyses show that the mean scores of all 19 items ranged from 3.52 to 4.30 . The standard deviations ranged from 0.51 to 0.74 and the skew and kurtosis indices from -0.40 to 0.30 and -0.56 to 1.08 respectively. Following Kline's [11] recommendations, the data in this study were considered to be univariate normal in Table 1. Table 2 shows the varimax rotated solution and the results of the principal component analysis of the 19-item, 4-factor scale.

Table 1. Descriptive of the 19 items proposed for the PEDS.

\begin{tabular}{lccccc}
\hline Item & Mean & SD & Skewness & Kurtosis & Range \\
\hline DE1 & 4.30 & 0.58 & -0.29 & 0.15 & $2-5$ \\
DE2 & 4.20 & 0.55 & 0.05 & -0.16 & $3-5$ \\
DE3 & 4.18 & 0.59 & -0.32 & -0.52 & $2-5$ \\
DE4 & 4.28 & 0.51 & 0.30 & 0.40 & $2-5$ \\
DE5 & 4.20 & 0.57 & -0.16 & 10.08 & $2-5$ \\
DE6 & 4.09 & 0.61 & -0.40 & -0.30 & $2-5$ \\
AN1 & 3.52 & 0.74 & 0.02 & -0.16 & $2-5$ \\
AN2 & 3.60 & 0.66 & -0.09 & -0.04 & $2-5$ \\
AN3 & 3.61 & 0.63 & -0.31 & -0.17 & $2-5$ \\
AN4 & 3.68 & 0.65 & -0.05 & 0.20 & $1-5$ \\
VI1 & 3.72 & 0.74 & -0.22 & 0.50 & $1-5$ \\
VI2 & 3.71 & 0.72 & -0.40 & 0.45 & $1-5$ \\
VI3 & 3.83 & 0.72 & -0.30 & 0.26 & $2-5$ \\
VI4 & 3.77 & 0.67 & -0.36 & -0.56 & $2-5$ \\
VI5 & 3.79 & 0.70 & 0.09 & -0.25 & $2-5$ \\
VI6 & 3.53 & 0.64 & 0.15 & 0.30 & $1-5$ \\
ST1 & 3.59 & 0.72 & -0.37 & -0.25 & $2-5$ \\
ST2 & 3.86 & 0.71 & -0.16 & -0.13 & $2-5$ \\
ST3 & 3.57 & 0.72 & -0.33 & & \\
\hline
\end{tabular}


Table 2. Rotated factor loadings, Cronbach's alpha and eigenvalues for the four factors of PEDS ${ }^{\mathrm{a}}$.

\begin{tabular}{|c|c|c|c|c|}
\hline Item & $\mathrm{DE}$ & AN & VI & ST \\
\hline \multicolumn{5}{|l|}{$\begin{array}{l}\text { Factor 1: Description }(\mathrm{DE}) \\
\qquad \alpha=0.90 \text { eigenvalue }=7.66\end{array}$} \\
\hline I like to write down what happened with my life. & 0.807 & & & \\
\hline I can write details about my experiences. & 0.795 & & & \\
\hline I know how to organize my PLN journals. & 0.791 & & & \\
\hline I read carefully about other's commends. & 0.768 & & & \\
\hline I feel it right to put on my knowledge on PLN. & 0.718 & & & \\
\hline Writing journals are important for me to record my life experiences. & 0.710 & & & \\
\hline \multicolumn{5}{|l|}{$\begin{aligned} \text { Factor 2: Analysis }(\mathrm{AL}) & \\
& \alpha=0.86 \text { eigenvalue }=2.32\end{aligned}$} \\
\hline I know why I flag the opinions on my PLNs. & & 0.797 & & \\
\hline I compare different ideas of my own. & & 0.769 & & \\
\hline I compare other's commends with my opinions. & & 0.764 & & \\
\hline I try to figure out why people think differently. & & 0.758 & & \\
\hline \multicolumn{5}{|l|}{$\begin{array}{l}\text { Factor 3: Vision }(\mathrm{VI}) \\
\qquad \alpha=0.83 \text { eigenvalue }=1.39\end{array}$} \\
\hline I feel I can apply what I believe in the real life. & & & 0.795 & \\
\hline Some principles of mine are consistent. & & & 0.704 & \\
\hline The journals I wrote have impact on others' opinions. & & & 0.697 & \\
\hline The theories I develop explain well on my actions. & & & 0.614 & \\
\hline I know I can improve the world. & & & 0.559 & \\
\hline \multicolumn{5}{|l|}{$\begin{array}{l}\text { Factor 4: Strategy }(\mathrm{ST}) \\
\qquad \alpha=0.71 \text { eigenvalue }=1.09\end{array}$} \\
\hline I develop the steps to reach my goals. & & & & 0.866 \\
\hline I develop details to reflect on my PLN journals. & & & & 0.670 \\
\hline I had transformation experience on my journal writing experiences. & & & & 0.511 \\
\hline
\end{tabular}

${ }^{\mathrm{a} T h e}$ scale internal consistency reaches 0.91 .

Based on a literature review of typologies of personal epistemology development, and sophisticated statistical analyses, general definitions of the four theory forming stages for PLN users in this study are as follows:

(1) Description: Users write and describe what they experiences; and read what others' opinions.

(2) Analysis: Theory constructors compare their own ideas; and compare different sources of information.

(3) Vision: PLN users develop the impacts of their beliefs.

(4) Strategy development: Detailed steps of implementing their theories; and reach a transformation by PLN journal writings.

\subsection{Study 2: Validation}

\subsubsection{Participants}

The purpose of this study is to validate the factor analysis result of the 19-item PEDS. Participants in this study were 411 PLN users in Taiwan. The mean age of the participants was $28.96(\mathrm{SD}=8.12)$. The sample comprised 235 (57.18\%) female PLN users. All participants were volunteers and were not grant by extra points for grade or monetary reward. 


\subsubsection{Confirmatory Factor Analysis}

The confirmatory factor analysis (CFA) of this study was used to validate the factorial structure of the 19-item scale by the computer software LISREL 8.8. The model examined in this study was examined using maximum likelihood estimation (ML). The model fit assessed by six indices: $\chi^{2}$, as the $\chi^{2}$ is sensitive to sample size, the ratio of $\chi^{2}$ to its degree of freedom $\left(\chi^{2} / \mathrm{df}\right)$ was used, with a recommended value smaller than 5.0 [12]. Two absolute fit indices are reported as the standardized root mean square residual (SRMR) with a recommended value smaller than 0.05; and the root mean square error of approximation (RMSEA) with values less than 0.08 as acceptable fit [13]. Finally, the comparative fit index (CFI) and non-normed fit index (NNFI) with a recommended value larger than 0.95 [12] to indicate an acceptable level of model fit.

\subsubsection{Results}

The model fit of the factor model indicated a good model fit $\left(\chi^{2}=258.55, \mathrm{df}=129 ; \chi^{2} / \mathrm{df}=2 ; \mathrm{NNFI}=0.97\right.$; GFI $=0.97$; RMSEA $=0.081 ;$ SRMR $=0.056$ ). One item was erased (original VI4) while the $\lambda$ was too low $(0.42)$. With the good model fit indices, acceptable composite reliability and average variance extracted, this study provided support for convergent validity [14]. The inter-factor correlations $(\Phi)$ are between 0.50 and 0.73 , all smaller than the square root of AVE of each construct, indicating good discriminant validity. In addition, all standardized estimates had exceeded the recommended value of 0.50 [10]. The Cronbach's alpha for the instrument is 0.91 and the $\alpha$ for the four subscale are $0.90,0.86,0.83,0.71$ respectively. The factor loading coefficients, t-value for each item and composite reliability, average variance extracted of each construct are shown in Table 3.

\subsubsection{Measurement and Structure Model Analysis}

The measurement model produced good fit to the data: $\mathrm{CFI}=0.97$, NNFI $=0.96$, SRMR $=0.059$, RMSEA $=$ $0.07, \chi^{2}(160)=341.20, \mathrm{p}<0.001, \chi^{2} / \mathrm{df}=2.13$. We next tested the fit of the structural model. Analysis of the structural model yielded evidence of good fit: $\mathrm{CFI}=0.96, \mathrm{NNFI}=0.96, \mathrm{SRMR}=0.070, \mathrm{RMSEA}=0.078, \chi^{2}=$ $398.53, \mathrm{p}<0.001, \mathrm{df}=166, \chi^{2} / \mathrm{df}=2.40$. The structural model did not fit the data as well as the measurement model, $\Delta \chi^{2}(6)=57.33, \mathrm{p}<0.001$, suggesting the measurement model does not fully explain the relations among the factors.

Table 3. Factor loading coefficients, t-value, CR and AVE of PEDS.

\begin{tabular}{|c|c|c|c|c|}
\hline Item & $\lambda$ & $\mathrm{t}$-value & $\mathrm{CR}^{\mathrm{a}}$ & $\mathrm{AVE}^{\mathrm{b}}$ \\
\hline DE1 & 0.82 & 12.18 & \multirow{6}{*}{0.90} & \multirow{6}{*}{0.59} \\
\hline DE2 & 0.81 & 14.51 & & \\
\hline DE3 & 0.81 & 14.58 & & \\
\hline DE4 & 0.72 & 11.11 & & \\
\hline DE5 & 0.78 & 14.89 & & \\
\hline DE6 & 0.66 & 13.88 & & \\
\hline AN1 & 0.74 & 15.34 & \multirow{4}{*}{0.86} & \multirow{4}{*}{0.62} \\
\hline AN2 & 0.83 & 14.81 & & \\
\hline AN3 & 0.72 & 12.50 & & \\
\hline AN4 & 0.84 & 11.97 & & \\
\hline VI1 & 0.72 & 11.70 & \multirow{5}{*}{0.83} & \multirow{5}{*}{0.50} \\
\hline VI2 & 0.72 & 10.37 & & \\
\hline VI3 & 0.74 & 11.95 & & \\
\hline VI4 & 0.71 & 12.11 & & \\
\hline VI5 & 0.64 & 12.39 & & \\
\hline ST1 & 0.84 & 7.82 & \multirow{3}{*}{0.80} & \multirow{3}{*}{0.57} \\
\hline ST2 & 0.75 & 11.52 & & \\
\hline ST3 & 0.67 & 10.09 & & \\
\hline
\end{tabular}

${ }^{\mathrm{a}} \mathrm{CR}$ refers to the composite reliability, recommended value $>0.70$; ${ }^{\mathrm{b}} \mathrm{AVE}$ refers to the average variance extracted, recommended value $>$ 0.50 . 
As shown in Figure 1, this study found support for the specific predictions that the perceived equality contribute to the prediction of each stages of theory construction. Equality accounted for $51 \%$ of the description, $59 \%$ of the analysis, $67 \%$ of the vision, and $61 \%$ of the strategy, respectively.

\section{Hypothesis Analysis}

\section{Gender Differences}

In addition to the PEDS, this survey also ask participant of how they perceive the equality of their learning environment. The questions items are "I feel I have the equal power with the peers who give comments", and "I accept the knowledge which has been posted on the Internet". This study first performed a t-test on the set of predictor and criterion variables, finding significant $(\mathrm{p}<0.001)$ omnibus difference between gender on descript, vision and perceived equality $(\mathrm{t}=5.21,2.21$, and 6.45 respectively) as shown in Table 4, female PLN users reported significantly $(\mathrm{p}<0.05)$ higher description and vision, but perceived lower equality from their learning context and knowledge content. Scale means, standard deviations, and intercorrelations for the full sample are reported in Table 5.

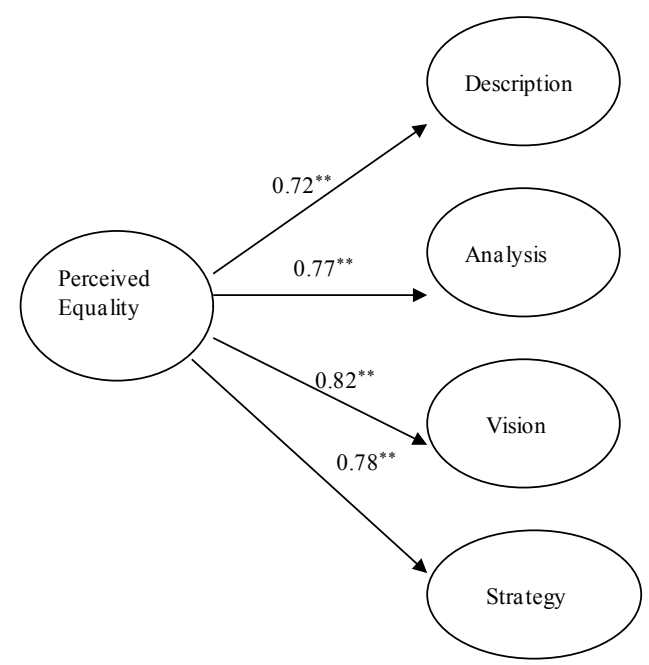

Figure 1. Structure model and the estimate coefficients.

Table 4. Variables as a function of PLN users' gender.

\begin{tabular}{cccc}
\hline & Women & Men \\
\hline Variable & $\mathrm{M}(\mathrm{SD})(\mathrm{n}=235)$ & $\mathrm{M}(\mathrm{SD})(\mathrm{n}=176)$ & $4.18(0.43)$ \\
\hline Description & $4.25(0.48)$ & $3.68(0.57)$ & $3.21^{* *}$ \\
Analysis & $3.72(0.55)$ & $3.58(0.52)$ & 3.06 \\
Vision & $3.81(0.49)$ & $3.16(0.59)$ & 0.98 \\
Strategy & $3.09(0.56)$ & $3.74(0.70)$ & $6.45^{* *}$ \\
\hline
\end{tabular}
${ }^{*} \mathrm{p}<0.05 ;{ }^{* *} \mathrm{p}<0.01$.

Table 5. Scale means, standard deviations, and intercorrelations for all variables.

\begin{tabular}{|c|c|c|c|c|c|c|c|}
\hline Variables & M & $\mathrm{SD}$ & 1 & 2 & 3 & 4 & 5 \\
\hline 1. Description & 4.21 & 0.46 & 0.90 & & & & \\
\hline 2. Analysis & 3.60 & 0.56 & $0.44^{* *}$ & 0.86 & & & \\
\hline 3. Vision & 3.71 & 0.54 & $0.43^{* *}$ & $0.63^{* *}$ & 0.83 & & \\
\hline 4. Strategy & 3.11 & 0.57 & $0.51^{* *}$ & $0.39^{* *}$ & $0.49^{* *}$ & 0.71 & \\
\hline 5. Equality & 3.39 & 0.72 & $0.40^{* *}$ & $0.35^{* *}$ & $0.30^{* *}$ & $0.21^{* *}$ & 0.69 \\
\hline
\end{tabular}

${ }^{* *} \mathrm{p}<0.01$; Note: the diagonal represents variable constructs' internal consistence. 


\section{Discussion and Conclusion}

The factor structure of the PEDS was validated in this study. The four stages of how people construct their personal theory on their own PLNs are description, analysis, vision and strategy. This study also reveals that perceived equality in PLN environment also positively impacts the stages of theory construction especially for the vision. Vision needs imagination and implementation. The perception of power equality can promote the vision stage posted once the individual feel unconstrained in their thoughts. The result also demonstrated gender difference in perceived equality, description and vision. Female writers may feel less equal toward the comments and existing information presented to them. This reflects the inequality of gender in a patriarchy society [4]. The result was derived from a sample comprised participants mainly from Taiwan. From the view of diversity, the result may provide a start for the future studies applying in different culture and ethnic groups. The generalization of this research result, hence, needs validation by future studies. Further model invariance analysis could also be done to see how gender differs in personal epistemology development process.

\section{Acknowledgements}

Funding of this research work was supported by National Science Council, Taiwan, under Grant Number 992511-S-011-003-MY2 and 101-2511-S-007-003-MY2.

\section{References}

[1] Amis, D. (2002) Web Logs: Online Navel Gazing? http://www.netfreedom.Org/news.asp?item=190

[2] Technorati (2008) State of the PLN Osphere Report. http://technorati.com

[3] Bunch, C. and Frost, S. (2000) "Empowerment," and "Women's Human Right". Routledge International Encyclopedia of Women's Studies, New York.

[4] Tisdell, E.J. (1998) Poststructural Feminist Pedagogies: The Possibilities and Limitations of Feminist Emancipatory Adult Learning Theory and Practice. Adult Education Quarterly, 48, 139-156. http://dx.doi.org/10.1177/074171369804800302

[5] Kerlinger, F.N. (1986) Foundations of Behavioral Research. 3rd Edition, Holt, Rinehart and Winston, New York.

[6] Seley, H. (1964) From Dream to Discovery: On Being a Scientist. McGraw-Hill, New York.

[7] Bunch, C. (1981) Building Feminist Theory: Essays from Quest. Edited with Flax, Freeman, Hartsock, and Mautner, Longman Inc., New York.

[8] Hayes, E. (1989) Insight from Women's Experiences for Teaching and Learning. New Directions for Continuing Education, 48, 55-66. http://dx.doi.org/10.1002/ace.36719894307

[9] Kaiser, H.F. (1960) The Application of Electronic Computers to Factor Analysis. Educational and Psychological Measurement, 20, 141-151. http://dx.doi.org/10.1177/001316446002000116

[10] Kline, R.B. (2005) Principles and Practice of Structural Equation Modeling. 2nd Edition, The Guilford Press, New York.

[11] Hair, Jr., J.E., Black, W.C., Babin, B.J. and Anderson, E. (2010) Multivariate Data Analysis. 7th Edition, Prentice-Hall, Upper Saddle River.

[12] Hu, L. and Bentler, P.M. (1999) Cutoff Criteria for Fit Indexes in Covariance Structure Analysis: Conventional Criteria versus New Alternatives. Structural Equation Modeling, 6, 1-55. http://dx.doi.org/10.1080/10705519909540118

[13] MacCallum, R.C., Browne, M.W. and Sugawara, H.M. (1996) Power Analysis and Determination of Sample Size for Covariance Structure Modeling. Psychological Methods, 1, 130-149. http://dx.doi.org/10.1037/1082-989X.1.2.130

[14] Maruyama, G.M. (1988) Basics of Structural Equation Modeling. Sage, Thousand Oaks. 
Scientific Research Publishing (SCIRP) is one of the largest Open Access journal publishers. It is currently publishing more than 200 open access, online, peer-reviewed journals covering a wide range of academic disciplines. SCIRP serves the worldwide academic communities and contributes to the progress and application of science with its publication.

Other selected journals from SCIRP are listed as below. Submit your manuscript to us via either submit@scirp.org or Online Submission Portal.
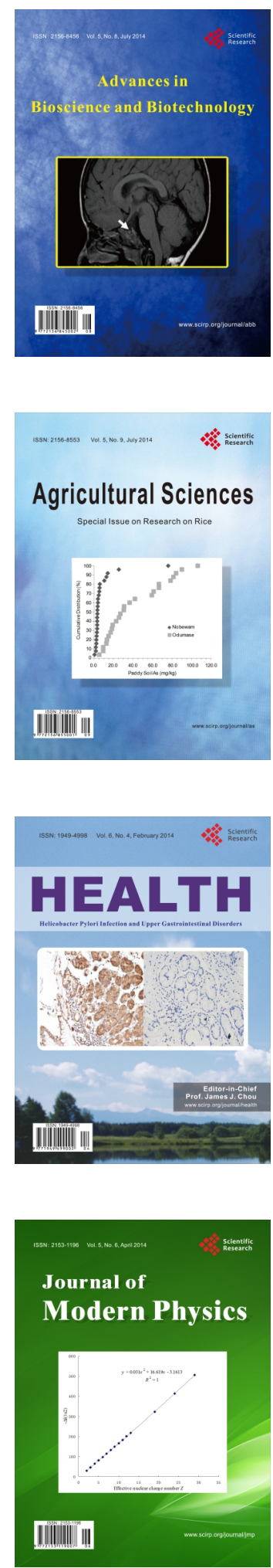
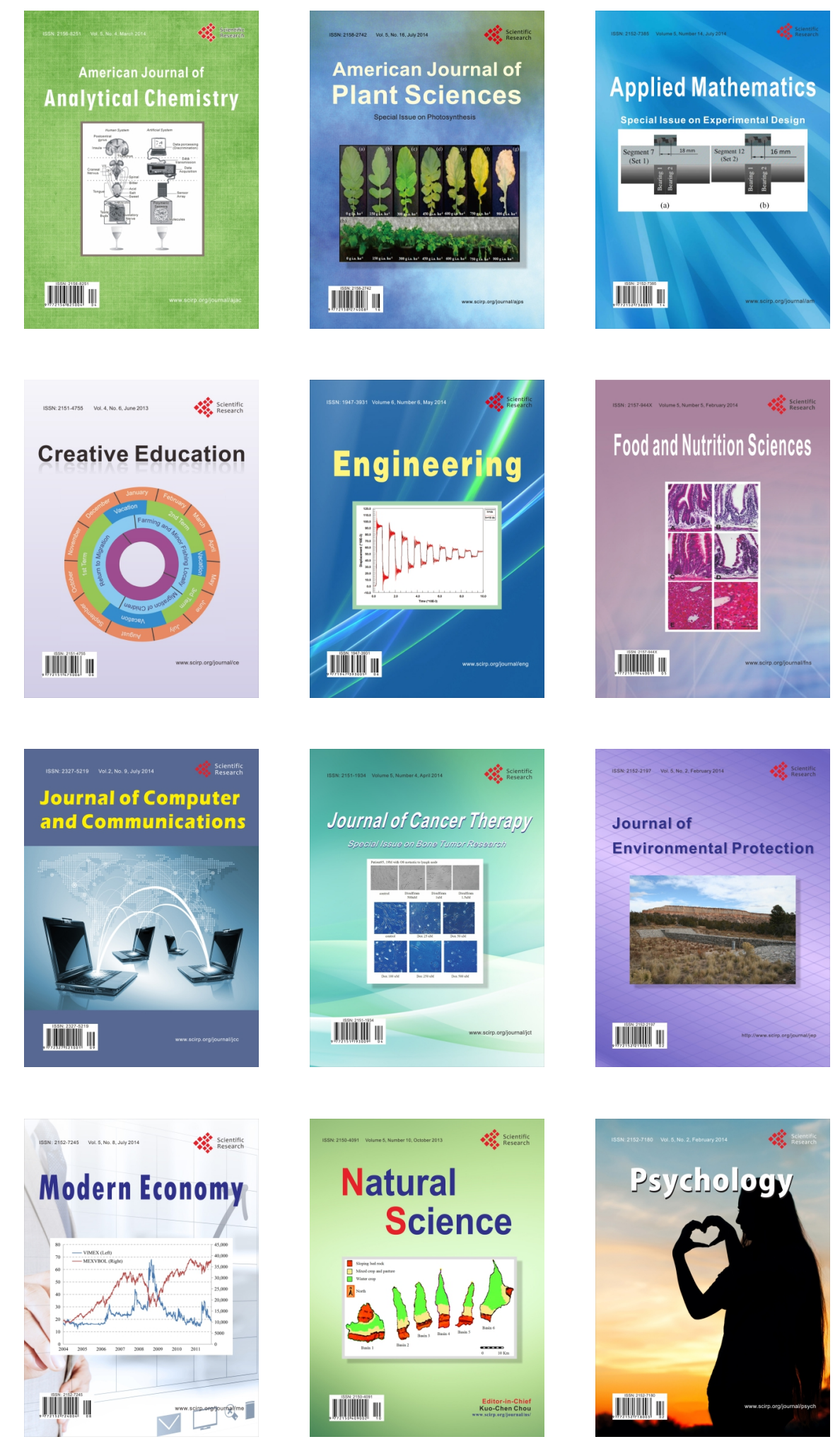